\title{
Response of the Earth's Lower Ionosphere to Solar Flares and Lightning-Induced Electron Precipitation Events by Analysis of VLF Signals: Similarities and Differences
}

\author{
Aleksandra Kolarski ${ }^{1}$, Vladimir A. Srećković ${ }^{2}$ (D) and Zoran R. Mijić ${ }^{2, *(D)}$ \\ 1 Technical Faculty Mihajlo Pupin, University of Novi Sad, Đure Đakovića bb, 23000 Zrenjanin, Serbia; \\ aleksandra.kolarski@tfzr.rs \\ 2 Institute of Physics Belgrade, University of Belgrade, Pregrevica 118, 11080 Belgrade, Serbia; vlada@ipb.ac.rs \\ * Correspondence: zoran.mijic@ipb.ac.rs
}

check for

updates

Citation: Kolarski, A.; Srećković, V.A.; Mijić, Z.R. Response of the Earth's Lower Ionosphere to Solar Flares and Lightning-Induced Electron Precipitation Events by Analysis of VLF Signals: Similarities and Differences. Appl. Sci. 2022, 12, 582. https://doi.org/10.3390/ app12020582

Academic Editor: Amalia Miliou

Received: 25 November 2021

Accepted: 5 January 2022

Published: 7 January 2022

Publisher's Note: MDPI stays neutral with regard to jurisdictional claims in published maps and institutional affiliations.

Copyright: (c) 2022 by the authors. Licensee MDPI, Basel, Switzerland. This article is an open access article distributed under the terms and conditions of the Creative Commons Attribution (CC BY) license (https:// creativecommons.org/licenses/by/ $4.0 /)$.

\begin{abstract}
The lower ionosphere influences the propagation of electromagnetic (EM) waves, satellite and also terrestrial (anthropic) signals at the time of intense perturbations and disturbances. Therefore, data and modelling of the perturbed lower ionosphere are crucial in various technological areas. An analysis of the lower ionospheric response induced by sudden events during daytime-solar flares and during night-time-lightning-induced electron precipitation was carried out. A case study of the solar flare event recorded on 7 September 2017 and lightning-induced electron precipitation event recorded on 16 November 2004 were used in this work. Sudden events induced changes in the ionosphere and, consequently, the electron density height profile. All data are recorded by Belgrade (BEL) radio station system and the model computation is used to obtain the ionospheric parameters induced by these sudden events. According to perturbed conditions, variation of estimated parameters, sharpness and reflection height differ for analysed cases. Data and results are useful for Earth observation, telecommunication and other applications in modern society.
\end{abstract}

Keywords: atmosphere; radio signal; disturbances; data; modelling

\section{Introduction}

The ionosphere, as a huge layer of the atmosphere, has physical and chemical properties that depend on the incident radiation and local energetic processes [1,2]. In particular, the lower ionospheric region and the fluctuations of its parameters are very important for human life and many activities on Earth and require continuous measurements, observations and available information [3].

In-situ observations of the lower ionospheric layers are difficult and expensive and, consequently, remote sensing measurements are mainly used for investigating this region $[4,5]$. High-energy events, triggered from an external source or inside the atmosphere, can induce ionospheric disturbances and as a consequence affect all processes within [6].

For example, during solar flares (SFs) the increase in the ionospheric electron concentration at all altitudes is noticeable. Solar flares are giant explosions on the surface of the Sun when a huge amount of electromagnetic energy is released across the entire electromagnetic spectrum [7]. The enhanced extreme ultraviolet (EUV) radiation is absorbed at higher altitudes ionizing the E (90-150 km above Earth's surface during daytime conditions) and F (160-400 km, same) regions of the ionosphere (see e.g., [8]). During SFs, electromagnetic radiation within soft X-rays in a wavelength range of $0.1-0.8 \mathrm{~nm}$, significantly oversteps the ionization of the Lyman-a spectral line $121.6 \mathrm{~nm}$ and cosmic rays, becoming a major source of ionization at a range of altitudes corresponding to the $D$ region (50-90 km, same), causing enhanced ionization and absorption of the EM waves that propagate within the Earth-ionosphere waveguide $[9,10]$. As a result of radiation effects, 
the solar induced ionospheric disturbances and plasma irregularities cause perturbations in the amplitude and phase of radio signals.

Furthermore, some processes create localised areas of increased electron density in the low ionosphere and thus change its properties. Radio waves, generated by atmospheric discharge and propagating along geomagnetic field lines into the plasmasphere, get into transversal cyclotron resonance with energetic electron beams (30-300 keV) moving in the opposite direction. As a consequence of such interaction, electron precipitation into the atmosphere takes place. Electron precipitation produces localised areas of increased electron density in the low ionosphere (on heights corresponding to D-region heights of 50-90 km [11-13]), known as localised ionization enhancement (LIE) [14]. Perturbations in very low frequency (VLF) propagation, known as trimpi events, can be explained by formation of such areas. Classic trimpi events [15] are phase delay and/or amplitude perturbations of VLF signals propagating in the Earth-ionosphere waveguide. Whistlers occur about one second after a corresponding atmospheric discharge and propagate in the magnetosphere along geomagnetic field lines [16]. Electron precipitation, caused by ducted whistlers, is explained in [17]. Since disturbances of VLF signals are a consequence of electron precipitation caused by atmospheric discharges, they are named as lightning-induced electron precipitation events (LEP). In addition to the above-mentioned phenomena, which can be detected as disturbances in VLF propagation, there are a number of other phenomena which can be optically detected in areas above thunderclouds. The formation of ducts of enhanced electroconductivity between thunderclouds and the ionosphere is connected with such phenomena [18-20]. Trimpi perturbations can be simultaneously monitored on multiple adjacent traces of VLF signals. Based on adjacent VLF signals recordings comparison, LIE dimensions and spatial position can be estimated by numerical modelling, depending on the transmitter frequency, VLF signal great circle path (GCP) length and position of LIE in relation to the VLF signal path.

Disturbances in propagation of VLF radio signals at the Belgrade station BEL (located at the Institute of Physics Belgrade $\left(44.85^{\circ} \mathrm{N}, 20.38^{\circ} \mathrm{E}\right)$, Serbia) were observed and the model computation is used to obtain the atmosphere parameters induced by these sudden events. According to perturbed conditions, variation of estimated parameters, sharpness and reflection height differ for the analysed cases.

\section{Methods}

For the examination of the ionospheric composition, altitudes, locations and other properties, experts usually make use of satellites equipped with suitable sensors, GPS, sonde, radars, various optical instruments, or balloons, rocket probes, etc. A widely used technique for remote sensing of the Earth's ionosphere exploits radio signals (e.g., [21-24]), and for altitude range that corresponds to the ionospheric lowest layer, i.e., the D region, VLF radio signal range is preferred (e.g., [25-30]). Remote sensing of the lower ionosphere by utilisation of radio signals in the VLF range is based on the hop wave theory (see, e.g., [31-34]). These techniques are successfully used for exploration of Earth's lower ionosphere's response to a number of processes, with their origin from extra-terrestrial to terrestrial environments (e.g., [35-41]).

The methodology used and results of mid-latitude lower ionosphere diagnostic obtained by this technique, based on VLF radio signals recorded at the Belgrade receiver site, in cases of regular and irregular solar-terrestrial conditions, can be found in, e.g., $[23,37,39,42-50]$. In our study, at the ionosphere altitudes $50-90 \mathrm{~km}$ (D region), measurements rely on radio wave propagation technique, i.e., monitoring of phase and amplitude of VLF radio signals. For this reason, the perturbation of VLF phase delay and amplitude was estimated as a difference between values of the perturbed signal induced by external disturbance and signal in the normal unperturbed conditions. The details are described in the next section. 


\section{Used Numerical Model}

A standard technique for retrieving ionospheric parameters during sudden ionospheric disturbances (SIDs) is based on comparing the registered amplitude and phase changes with the equal values computed by Long Wavelength Propagation Capability (LWPC) software [51], as interpreted in $[9,10]$. To determine electron density from recorded amplitude and phase variations, a trial and error procedure can be utilized, with the density profile being changed until the LWPC predicted amplitude and phase matched the monitored data (see, e.g., [42]). As a result, the calculated beta and $H^{\prime}$ values can be employed in subsequent computations and simulations (e.g., electron gain and electron loss processes coefficient, etc.).

\section{Results}

\subsection{Lower Ionosphere during SF Event}

The monitoring and investigation of VLF data has been carried out simultaneously with the examination of the correlative incoming solar X-ray fluxes collected from the Geostationary Operational Environmental Satellite (GOES).

In the presence of SIDs, a standard numerical procedure for the estimation of plasma parameters is based on comparison of the recorded changes of amplitude and phase with the matching values acquired in simulations by the LWPC numerical software package as explained in $[9,44,46,47]$.

We studied data for 7 September 2017, as an example of a day with strong X1.3 class SFs that caused SID and seriously affected the VLF signal. It should be noted that the development to the flux of X-ray lasted almost one hour.

The monitored and simulated changes of amplitude $(\Delta A)$ and phase delay $(\Delta P)$ compared to normal day-time levels for a signal emitted on frequency $24 \mathrm{kHz}$ from Cutler $\left(44.65^{\circ} \mathrm{N}, 67.30^{\circ} \mathrm{W}\right), \mathrm{ME}$, USA, with codename NAA measured at the BEL site is presented in Figure 1. Besides the good agreement between simulated and monitored data, X-ray flux peak and VLF signal perturbation happened synchronously i.e., energetic radiation perturbed the ionosphere which, in turn, caused the activation of disturbances in radio signal.
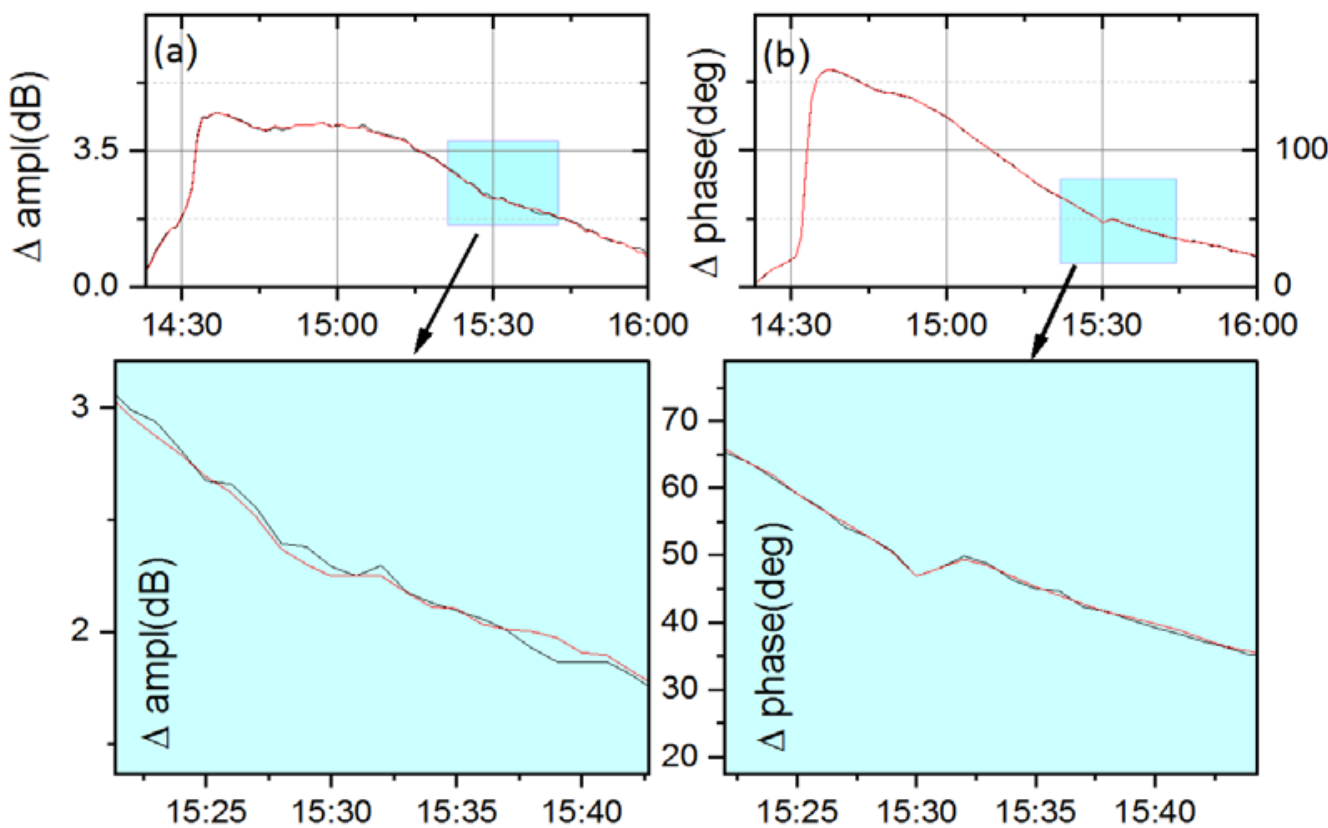

Figure 1. Measured and simulated amplitude (a), and phase delay (b) excesses of NAA radio signal during X1.3 class SF on 7 September 2017. 
Figure 2 presents obtained values of effective reflection height $H^{\prime}$ and the sharpness $\beta$ during almost two hours, i.e., during occurrences of SFs on 7 September 2017. During $\mathrm{X} 1.3$ class SFs, the shape of reflection height is in anticorrelation and the sharpness is in correlation with $\mathrm{X}$-ray flux.
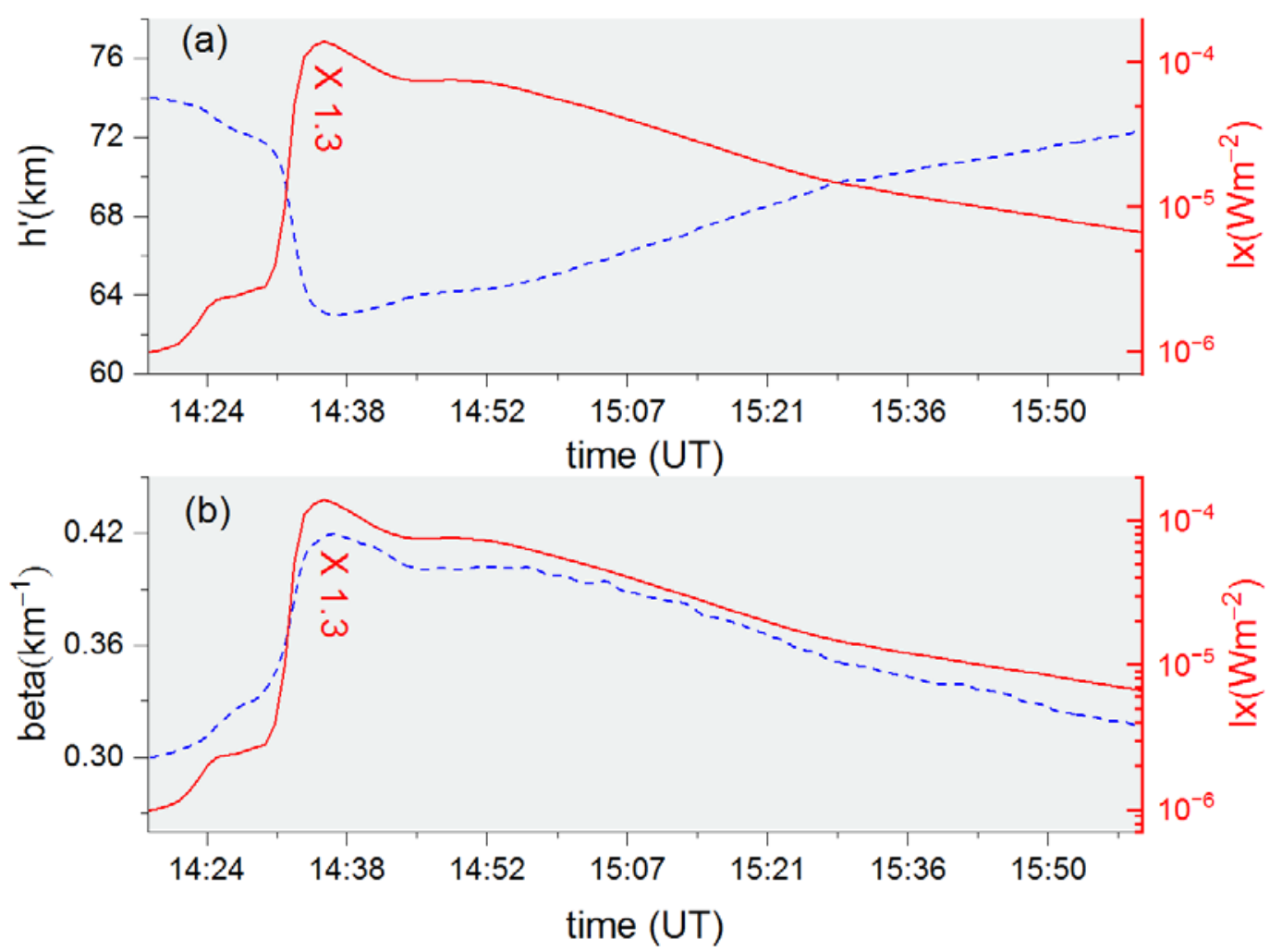

Figure 2. Parameters $H^{\prime}(\mathbf{a})$, and $\beta$ (b) and X-ray flux (right axis) during occurrence of X1.3 class SF on 7 September 2017.

The change of the reflection height is a normal behaviour, i.e., after the beginning of SFs the reflection height decreases to a minimum and after peaks of X-ray flux it rises to the preflare value (see Figure 2a). The shape of sharpness is correlated with the shape of recorded X-ray flux increase. During the X1.3 SF, the sharpness increases to a maximum and after the SF peak (14:36 UT) it decreases to the pre-flare value (Figure 2b). At peak time (14:36 UT), the X-ray flux is $I x=1.3 \times 10^{-4} \mathrm{Wm}^{-2}$, and the $H^{\prime}$ lowers by $13 \mathrm{~km}$ to a value $H^{\prime} \sim 63 \mathrm{~km}$. The sharpness values increase to $0.42 \mathrm{~km}^{-1}$ at peak time 14:36 UT on 7 September 2017.

Electron density profile changes can demonstrate the variation in distribution of ionization at the D-layer due to SFs. Figure 3a presents the simultaneous change of X-ray flux, and the corresponding $\mathrm{Ne}$ (Figure $3 \mathrm{~b}$ ) obtained at reference height $74 \mathrm{~km}$ versus UT during occurrence of X1.3 class SF on 7 September 2017. It can be seen that the electron density is in correlation with X-ray flux and, Ne increased by almost two orders of magnitude during the $\mathrm{X} 1.3$ class SF.

The current study is important because most results concerning investigation in the Dregion are scattered and vary in order of magnitude (see $[9,23,52,53])$, thus it is necessary to take into account all the data and correct the existing data. Sudden events induce changes in the ionosphere and, consequently, the electron density height profile. It is useful to obtain new results by analysing the similarities and differences, especially for case studies, i.e., when solar flares last significantly longer and perturb the ionosphere in a specific way. An additional aim is the simultaneous analysis of the lower ionospheric response and electron density height profile variations in the lower ionosphere induced by sudden events during daytime solar flares and during night-time lightning-induced electron precipitation. 


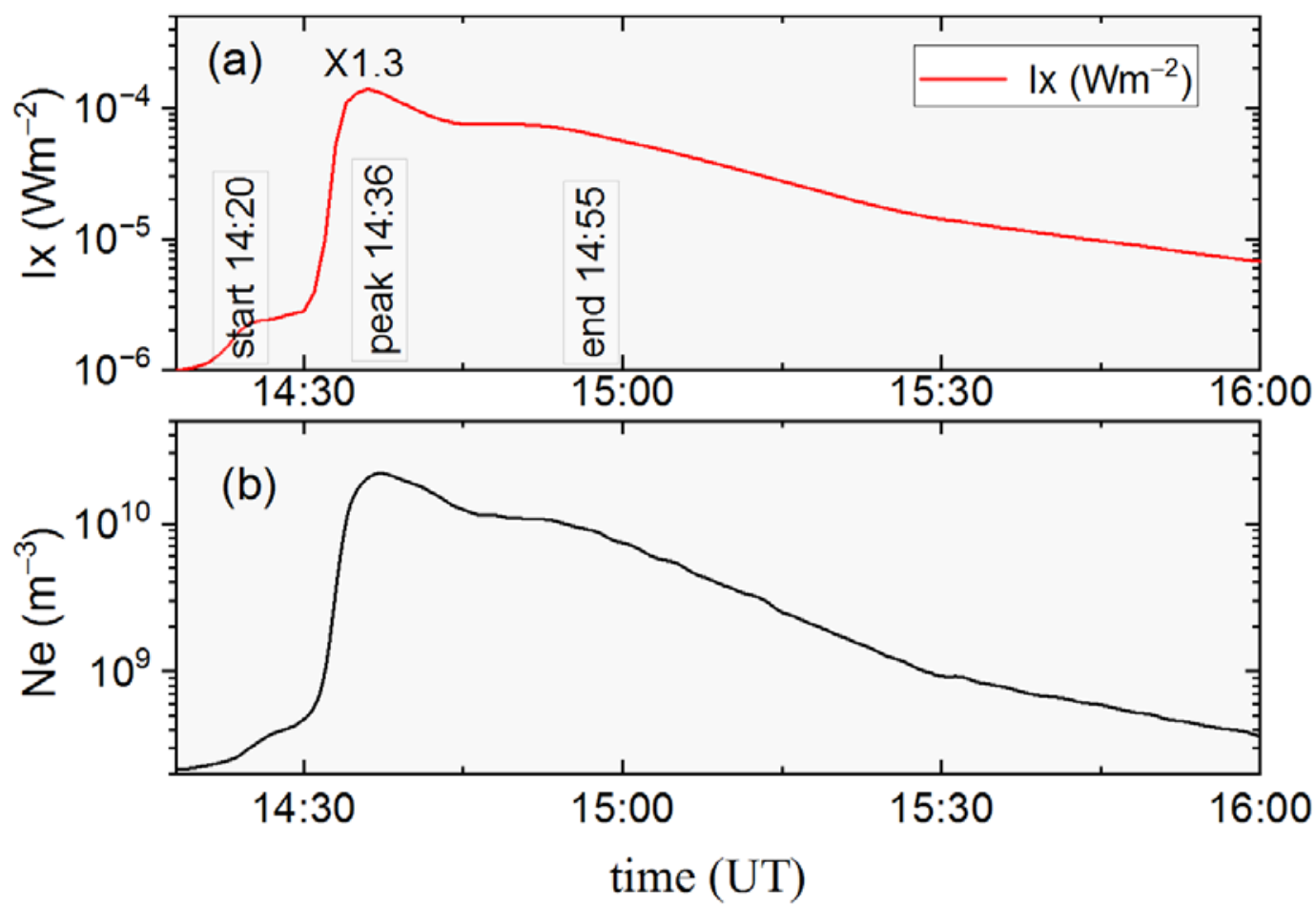

Figure 3. X-ray flux measured by the GOES satellite (a), and evaluated electron density profiles (b) during occurrence of X1.3 class SF on 7 September 2017.

\subsection{Signal Propagation Parameters during LEP Event}

Lightning-induced electron precipitation, i.e., LEP, is triggered by an extremely low frequency (VLF and ELF) portion of EM energy released by lightning discharges that manage to reach the Earth's magnetosphere and by propagating as whistler mode wave interactions with electrons from radiation belts forcing them to precipitate to lower altitudes of 60-120 km, causing an increase in electron density. Such localised and transient electron density enhancements in the D-region altitude range can produce significant amplitude and phase delay perturbations on narrowband VLF signals (with change in amplitude level up to $6 \mathrm{~dB}$ and in phase delay of about 20 degrees, typically with rise times up to $1 \mathrm{~s}$ and signal decay below $100 \mathrm{~s}$ ) propagating through or near-by the disturbed region (e.g., [18,48,54] and references therein). An LEP event occurred on 16 November 2004 and its impact on VLF signal traces NAA/24.0 kHz and GQD/22.1 kHz (signal with codename GQD emitted from Anthorn $\left.\left(52.40^{\circ} \mathrm{N}, 1.20^{\circ} \mathrm{W}\right), \mathrm{GB}\right)$ was selected for analysis. The presented LEP event is one of the typical LEPs recorded by the Belgrade VLF station, from those during the period 2008-2010 [48,55], similar in absolute perturbation amplitude change of up to $5 \mathrm{~dB}$ and phase delay of up to a few tens of degrees with maximal duration of up to two minutes. Amplitude (solid lines) and phase delay (dotted lines) registrations, with resolution $0.1 \mathrm{~s}$ on NAA and GQD signals, before, during and after the LEP event occurred on 16 November 2004 and are presented in Figure 4a,b, respectively. Moments at which amplitude and phase delay values for unperturbed (regular) and perturbed (irregular) ionospheric conditions in waveguide were read, are marked with red and blue arrows. 


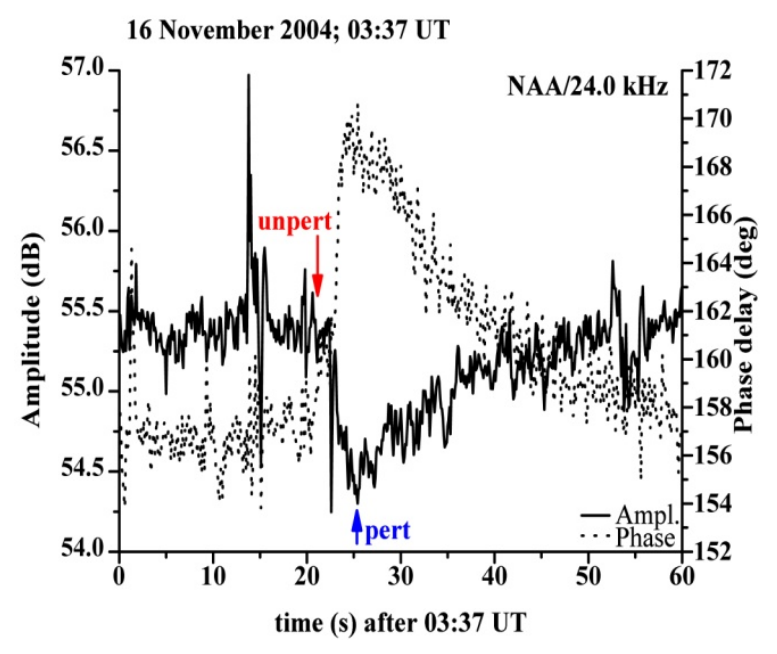

(a)

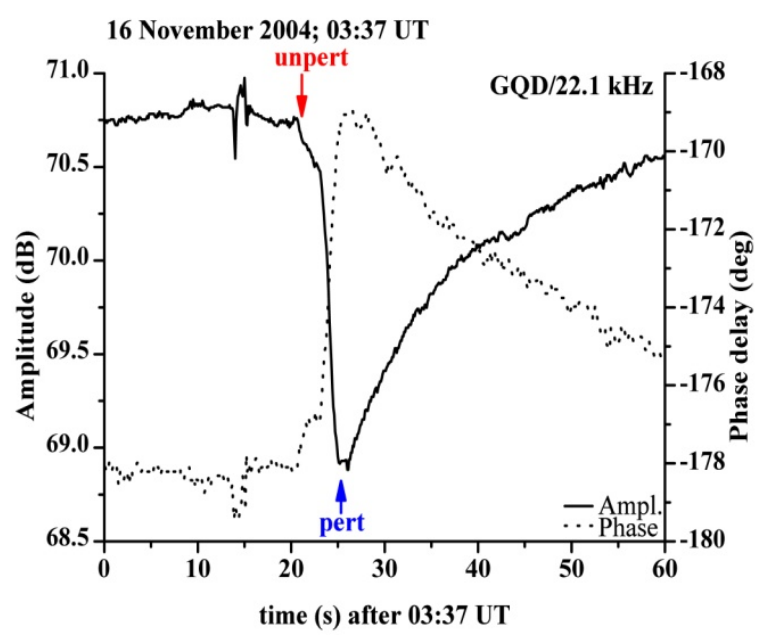

(b)

Figure 4. Amplitude (solid lines) and phase delay (dotted lines) time evolution before and during the LEP event occurred on 16 November 2004 on considered VLF signal traces: (a) NAA/24.0 kHz and (b) GQD/22.1 kHz.

\subsection{Modelling and Simulation during LEP Event}

NAA/24 kHz signal propagates along W-E direction and has a long (GCP distance $\mathrm{D}=6540 \mathrm{~km}$ ) and mostly oversea path, while GQD/22.1 kHz signal propagates along a short (GCP distance $\mathrm{D}=1980 \mathrm{~km}$ ) and mostly overland path (Figure 5). Disturbance occurred on both analysed signal traces, so it is reasonable to assume that ionospheric irregularity caused by an LEP event was located in the vicinity of the Belgrade receiver site. That is why, both for unperturbed and perturbed ionospheric conditions, the VLF propagation conditions were modelled only in that section of waveguide which is just a few hundred $\mathrm{km}$ away from the Belgrade receiver site $\left(44.85^{\circ} \mathrm{N}, 20.38^{\circ} \mathrm{E}\right)$.

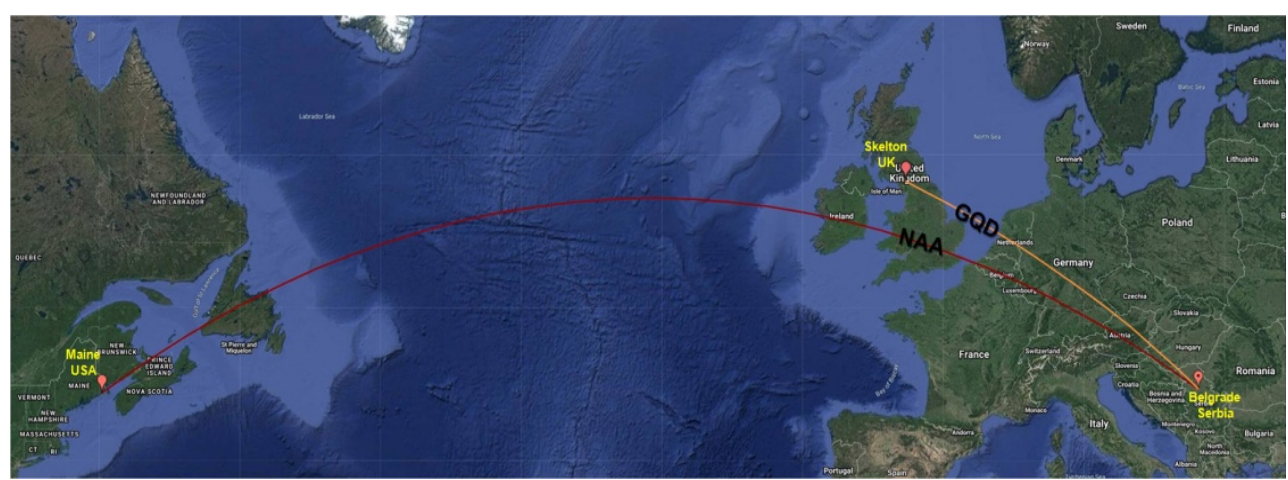

Figure 5. Possible paths for considered NAA/24.0 kHz (red) and GQD/22.1 kHz (yellow) VLF signals emitted towards Belgrade (Serbia) from Maine (USA) and Skelton (UK).

By means of Long Wavelength Propagation Capability computer program (LWPCv21) [51], the propagation paths of NAA/24.0 kHz and GQD/22.1 kHz signals were simulated and modelled. Best fitting pairs of parameters sharpness $\beta\left(\mathrm{km}^{-1}\right)$ and reflection height $H^{\prime}(\mathrm{km})$ were estimated in order to obtain values as close as possible to real measured values of the signals' phase delay (deg) and amplitude (dB) at the place of the receiver in Belgrade, for both cases of regular and disturbed ionospheric conditions in observed sections of waveguides. The estimated amplitude and phase delay values obtained by the LWPCv21 program are in good agreement with real measured values at 
the Belgrade receiver site (Table 1: first and third rows indicate unperturbed VLF signal values, while the second and fourth rows indicate the perturbed ones).

Table 1. Measured and estimated amplitude and phase delay values of NAA and GQD signals during the LEP event that occurred on 16 November 2004.

\begin{tabular}{|c|c|c|c|c|c|c|c|c|c|}
\hline \multirow{2}{*}{ VLF Signal } & \multirow{2}{*}{$\begin{array}{l}\text { Time UT } \\
0337 \text { UT + }\end{array}$} & \multicolumn{4}{|c|}{ Measured Values } & \multicolumn{4}{|c|}{ LWPC Simulation } \\
\hline & & $A(\mathrm{~dB})$ & $\Delta A(\mathrm{~dB})$ & $P\left({ }^{\circ}\right)$ & $\Delta P\left({ }^{\circ}\right)$ & $A(\mathrm{~dB})$ & $\Delta A(\mathrm{~dB})$ & $P\left({ }^{\circ}\right)$ & $\Delta P\left({ }^{\circ}\right)$ \\
\hline $\begin{array}{c}\mathrm{NAA} / 24.0 \mathrm{kHz} \\
\text { unperturbed values }\end{array}$ & $20.16 \mathrm{~s}$ & 55.42 & 0 & 157.08 & 0 & 55.63 & 0 & 173.18 & 0 \\
\hline $\begin{array}{l}\mathrm{NAA} / 24.0 \mathrm{kHz} \\
\text { perturbed values }\end{array}$ & $25.54 \mathrm{~s}$ & 54.37 & -1.05 & 170.03 & 12.95 & 54.62 & -1.01 & 195.02 & 21.84 \\
\hline $\begin{array}{c}\text { GQD/22.1 kHz } \\
\text { unperturbed values }\end{array}$ & $20.16 \mathrm{~s}$ & 70.70 & 0 & -178.05 & 0 & 70.40 & 0 & -214.88 & 0 \\
\hline $\begin{array}{l}\text { GQD/22.1 kHz } \\
\text { perturbed values }\end{array}$ & $25.54 \mathrm{~s}$ & 68.96 & -1.74 & -169.05 & 9 & 68.65 & -1.75 & -209.22 & 5.66 \\
\hline
\end{tabular}

The amplitude change $\Delta A(\mathrm{~dB})$, was obtained as the difference between the maximum value of the amplitude during the perturbation and the value of the amplitude in undisturbed signal. The phase delay change $\Delta P\left(^{\circ}\right)$ was obtained as the difference between the phase delay value that corresponds in time to the maximum value of the amplitude during the perturbation and phase delay value in the undisturbed signal interval that corresponds in time to the amplitude value chosen as unperturbed.

The model for the propagation of VLF signals within the Earth-ionosphere waveguide is defined by pairs of parameters $\left(\beta, H^{\prime}\right)$ and analytically described by equations for the calculation of the electron density height profile $N_{e}(z)\left(\mathrm{m}^{-3}\right)$ during daytime ionospheric conditions is given in [56]. The procedure for the computation of the electron density height profile is based on the equation for determining the electron density $N_{e}(z)\left(\mathrm{m}^{-3}\right)$ within the Earth-ionosphere waveguide during night-time conditions [14], where the electron density was calculated as a function of a certain pair of parameters $\beta$ and $H^{\prime}$, at the height $z(\mathrm{~km})$, based on the equation adapted for the nocturnal ionosphere [14]. Electron density height profile $N_{e}(z)\left(\mathrm{m}^{-3}\right)$, for given parameters $\beta$ and $H^{\prime}$, was calculated using the expression for the night-time ionosphere given by [14]:

$$
N_{e}\left(z, H^{\prime}, \beta\right)=1.86 \times 10^{11} \cdot \mathrm{e}^{-0.15 \cdot z} \cdot 78.57 \cdot \mathrm{e}^{\beta\left(z-H^{\prime}\right)}, \quad\left(\mathrm{m}^{-3}\right)
$$

Parameter $\beta$, for night-time ionospheric conditions, is in the range $0.47-0.50 \mathrm{~km}^{-1}$, while parameter $H^{\prime}$ is in the range $50-87 \mathrm{~km}$. Electron density was calculated at the reflection height, when $z=H^{\prime}$, and in that case (1) takes the form:

$$
N_{e}(z)=146.1402 \times 10^{11} \cdot \mathrm{e}^{-0.15 \cdot z}, \quad\left(\mathrm{~m}^{-3}\right)
$$

For modelling of parameters $\beta$ and $H^{\prime}$, the LWPC software was used. Detailed methodology, related to utilisation of LWPC software and VLF signal propagation modelling for different cases, can be found in $[14,29,56,57]$. Here, the procedure for modelling parameters $\beta$ and $H^{\prime}$ is only outlined. The basic parameters of the propagation medium, the sharpness of the upper boundary of the Earth-ionosphere waveguide $\beta$ and the height of the signal's reflection $H^{\prime}$ are related to the electron density $N_{e}(z)$ within the waveguide. Each change in the electron density in the waveguide changes the propagation parameters, amplitude and phase delay of the VLF signal. According to the LWPM model, for regular night-time conditions in the ionosphere, the program code takes the parameter $\beta$ as $0.40 \mathrm{~km}^{-1}$ and the parameter $H^{\prime}$ as $87 \mathrm{~km}$. However, to model the values of the amplitude and phase delay of the VLF signal, in each individual case, it is necessary to independently determine the appropriate parameter pairs $\left(\beta, H^{\prime}\right)$ as input parameters, so that the simulated values of the amplitude and phase delay obtained as output by the computation, correspond to 
the measured values of the amplitude and phase delay as close as possible, as the best fitting pair.

The procedure itself consists of numerous trials, in which parameter pairs $\left(\beta, H^{\prime}\right)$ are manually defined as input parameters and the program gives calculated amplitude and phase delay as the output values. Program output is dependent on numerous factors (such as signal frequency, bearing angle, receiver and transmitter locations, observed date and time, solar zenith angle, geomagnetic dip and electro-conductivity of lower waveguide boundary) that are imbedded as background data in calculations.

During night-time ionospheric VLF transmission, signal's amplitude is more stable than phase delay. During modelling, we focused on providing $\left(\beta, H^{\prime}\right)$ parameter pairs to obtain a really good agreement for relative amplitude change $\Delta A(\mathrm{~dB})$ for both analysed signals, while still obtaining a relatively good agreement for relative change in phase delay $\Delta P\left({ }^{\circ}\right)$. Simulated amplitude and phase delay values for NAA/24.0 kHz and GQD/22.1 $\mathrm{kHz}$ along GCP path, for the unperturbed (red) and perturbed (blue) state in waveguides on 16 November 2004, are presented in Figures 6 and 7, respectively. Areas of amplitude and phase delay changing near the Belgrade receiver site are framed and as zoomed in panels presented on the right.

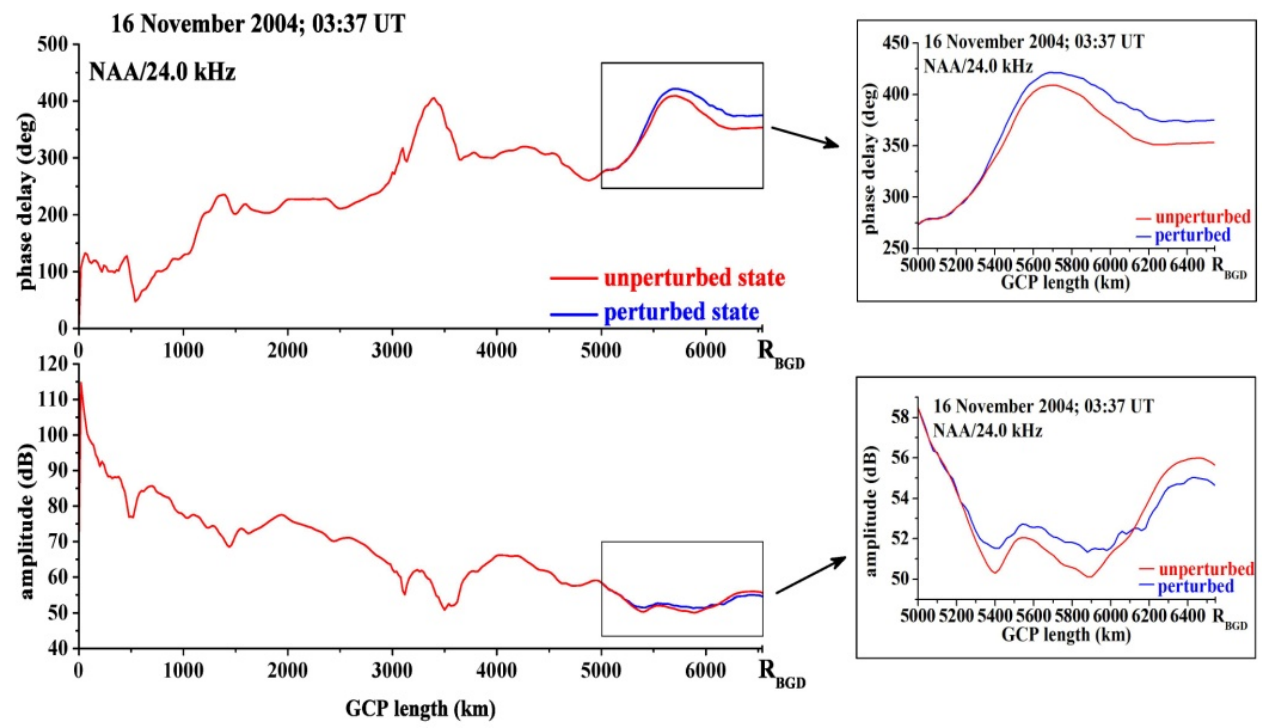

Figure 6. Simulated amplitude and phase delay along GCP path towards the Belgrade receiver, for unperturbed (red) and perturbed (blue) ionospheric states for NAA/24.0 kHz VLF signal waveguides, on 16 November 2004.

Parameters $\beta$ and $H^{\prime}$ changing along GCP path, for NAA $/ 24.0 \mathrm{kHz}$ (dashed lines) and GQD/22.1 kHz (dotted lines) VLF signal waveguides, for unperturbed (red) and perturbed (blue) ionospheric states, on 16 November 2004, are presented in Figure 8a,b, respectively (for waveguide sections of $1980 \mathrm{~km}$ along GCPs looking towards the Belgrade receiver; direction of view on $\mathrm{x}$ axis is presented by black arrows, pointing from left to right at the bottom scale when looking from transmitter $\mathrm{T}$ towards receiver $\mathrm{R}$ and pointing from left to right at the upper scale if looking from receiver $\mathrm{R}$ towards transmitter $\mathrm{T}$ ). Using the expression (1), for given parameter pairs $\left(\beta, H^{\prime}\right)$, electron density height profile $N_{e}(z)$ within ionospheric irregularity, in perturbed section of waveguide, for both analysed VLF signals, was calculated. Irregularity modelling indicates that both VLF signal traces, in some part of the waveguide, encounter an area of enhanced electron density. Electron density changing along GCP path, for NAA $/ 24.0 \mathrm{kHz}$ (dashed line) and GQD/22.1 kHz (dotted line) VLF signal waveguides, for unperturbed (red) and perturbed (blue) ionospheric states on 16 November 2004, are presented on Figure 9 (in length of 1980 km, as looking from Belgrade towards both transmitters). Electron densities along GCPs for unperturbed state (Figure 9-red) were calculated based on modelled parameter pairs 
$\left(\beta, H^{\prime}\right)$ posted as unperturbed for all characteristic altitudes (Figure 8-red), where parameters $\beta$ and $H^{\prime}$ undergo changes due to signal propagation within the unperturbed waveguide. Electron densities along GCPs for perturbed state (Figure 9-blue) were calculated based on modelled parameter pairs $\left(\beta, H^{\prime}\right)$ for all characteristic altitudes (Figure 8 -blue), where parameters undergo changes due to present irregularity and deviated from their posted unperturbed values.

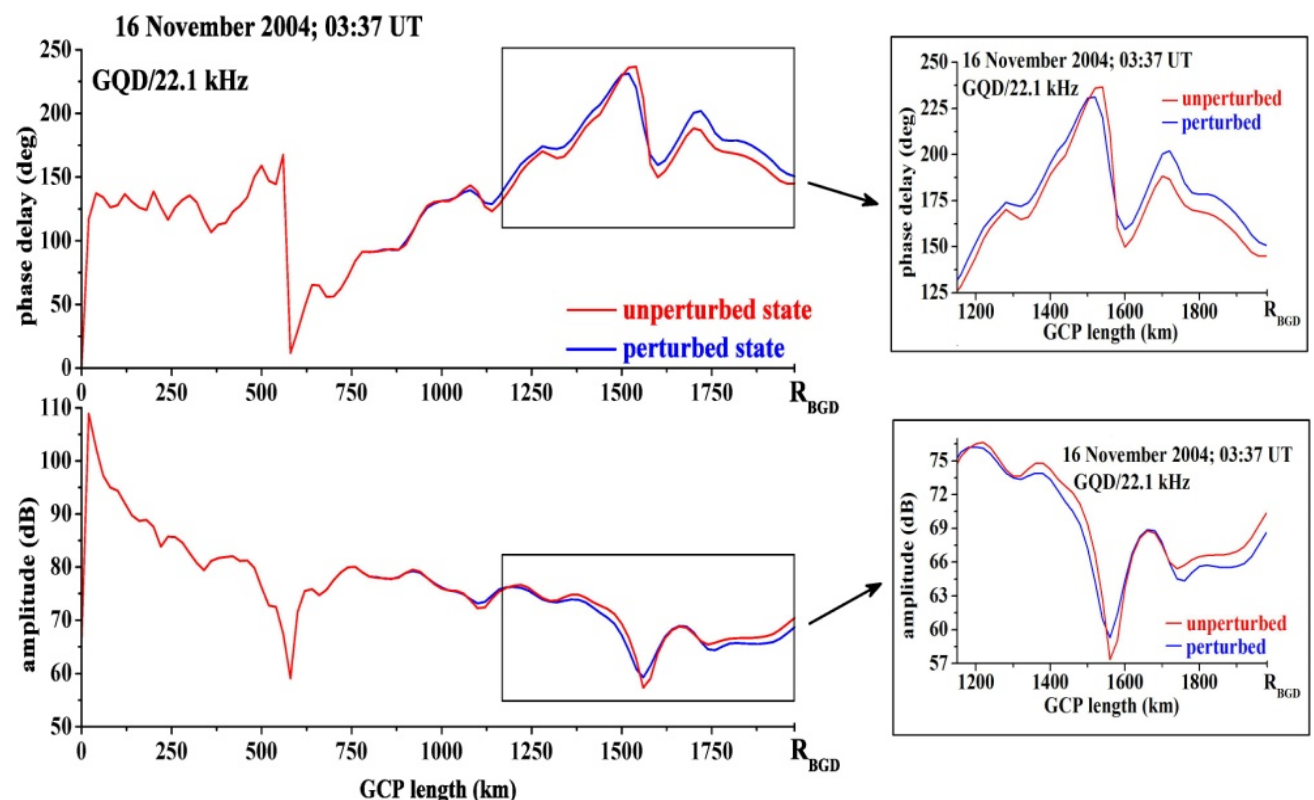

Figure 7. Simulated amplitude and phase delay along GCP path towards the Belgrade receiver, for unperturbed (red) and perturbed (blue) ionospheric states for GQD/22.1 kHz VLF signal waveguides, on 16 November 2004.

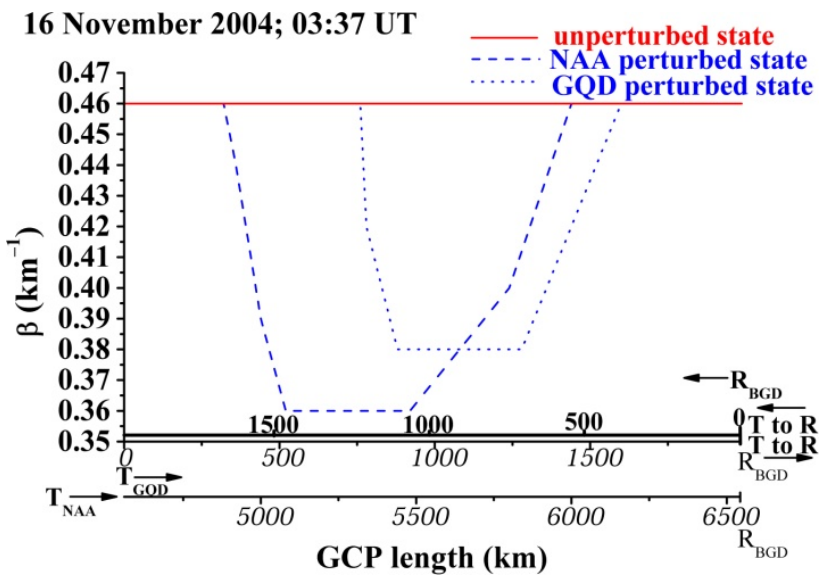

(a)

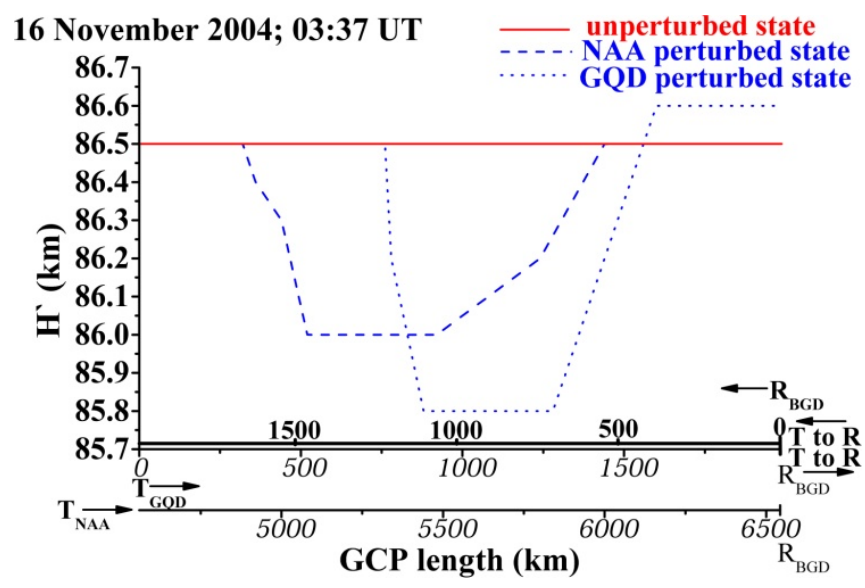

(b)

Figure 8. Parameter $\beta$ and $H^{\prime}$ changing along GCP path towards the Belgrade receiver, for considered VLF signal waveguides (NAA in dashed lines and GQD in dotted lines), for unperturbed (red) and perturbed (blue) ionospheric states, on 16 November 2004 ( $R$ is for receiver, $T$ is for transmitter, black arrows on $\mathrm{x}$ axis point the direction of view): (a) parameter $\beta$ and (b) parameter $H^{\prime}$.

Transmission in entirely nocturnal unperturbed ionospheric conditions, in the case of short GCPs is described by LWPC program usually with only one parameter pair $\left(\beta, H^{\prime}\right)$, while in the case of moderate GCPs usually with several parameter pairs $\left(\beta, H^{\prime}\right)$, along the entire path. It should be noted, that in this case, the unperturbed conditions were also modelled in order to provide the best possible match with real measured data. As 
already mentioned, since the perturbation was recorded on both monitored signals, in order to provide the best possible match with real measured data, in cases of perturbed conditions, sections of paths of several hundred $\mathrm{km}$ away from Belgrade towards transmitters, were modelled.

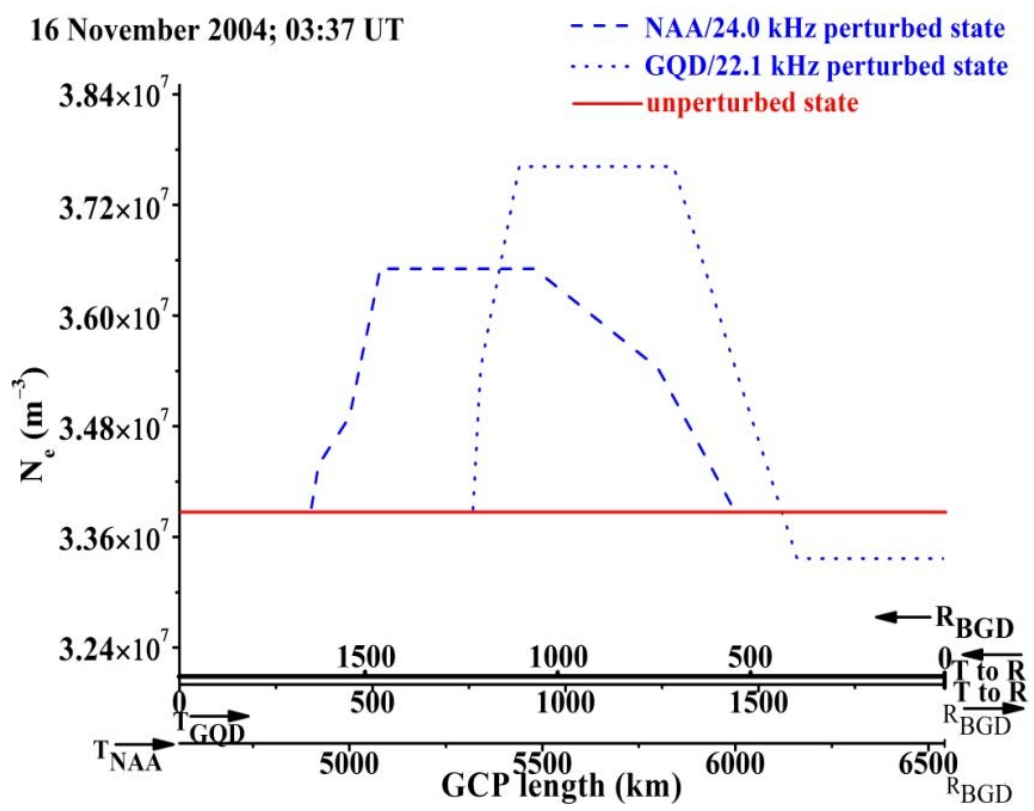

Figure 9. Electron density changing along GCP path towards the Belgrade receiver, for considered VLF signal waveguides (NAA/24.0 kHz in dashed line and GQD/22.1 kHz in dotted line), for unperturbed (red) and perturbed (blue) ionospheric states, on 16 November 2004 ( $R$ is for receiver, $T$ is for transmitter, black arrows on $\mathrm{x}$ axis point the direction of view).

On the NAA signal trace section, where ionospheric irregularity occurs, the calculated maximum value of electron density is $3.65 \times 10^{7} \mathrm{~m}^{-3}$, while in unperturbed ionospheric conditions, on the same NAA signal path section, it is $3.39 \times 10^{7} \mathrm{~m}^{-3}$. On the GQD signal trace section, where ionospheric irregularity occurs, the calculated maximum value of electron density is $3.76 \times 10^{7} \mathrm{~m}^{-3}$, while in unperturbed ionospheric conditions, on same GQD signal path section, it is $3.39 \times 10^{7} \mathrm{~m}^{-3}$. In Figure 9, the electron density height profiles in the altitude range $60-90 \mathrm{~km}$, for unperturbed and perturbed conditions due to the analysed LEP event were calculated at the reflection heights in the case of both monitored VLF signals (altitude $86 \mathrm{~km}$ for NAA and $85.8 \mathrm{~km}$ for GQD in Figure $8 \mathrm{~b}$ ), in the area of the most prominent electron density change along GCPs (e.g., at about $5300 \mathrm{~km}$ in the case of NAA and $1100 \mathrm{~km}$ in the case of the GQD signal looking from the transmitter towards the Belgrade receiver, i.e., at the approximate location of about $1100 \mathrm{~km}$ looking from Belgrade towards both transmitters) are given. Electron density $N_{e}(z)$ height profiles for GQD (at reflection height $85.8 \mathrm{~km}$ ) and NAA (at reflection height $86 \mathrm{~km}$ ) signals, calculated for the altitude range 60-90 km, for 16 November 2004, are given in Figure 10.

In order to create an easier and more convenient use of results presented in the analysis conducted in this paper, an expression for electron density $N e(z)$ at reflection height is introduced in the form of a polynomial function as given in the equation below:

$$
\log N e\left(z, H^{\prime}, \beta\right)=\sum_{i=0}^{1} a_{i} \cdot z^{i},
$$

where $z$ is height in $\mathrm{km}$, and dimensionless quantities take values of $a_{0}=-5.88339$ and $a_{1}=0.15635$. 


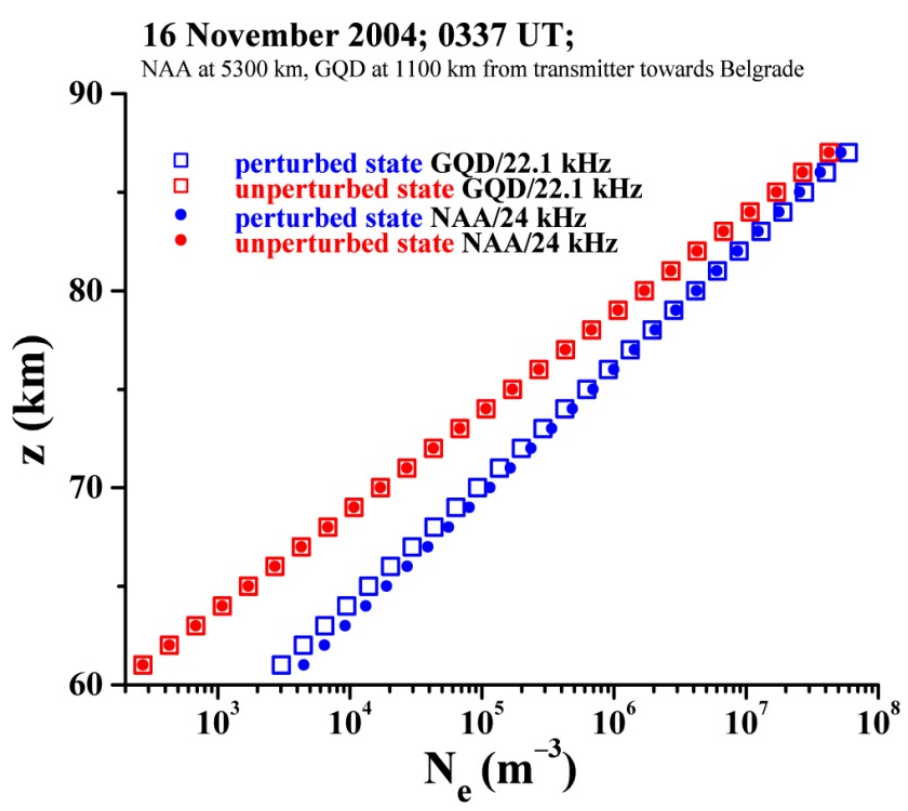

Figure 10. Electron density $N_{e}(z)$ height profiles for GQD (at reflection height $85.8 \mathrm{~km}$ ) and NAA (at reflection height $86 \mathrm{~km}$ ) signals, calculated for altitude range 60-90 km, for 16 November 2004, at 03:37 UT, in the area of the most prominent electron density change along GCPs at a location approximately $1100 \mathrm{~km}$ looking from Belgrade towards both transmitters. The unperturbed state for GQD signal is given in red hollow squares, the perturbed state for GQD signal is given in blue hollow squares, unperturbed state for NAA signal is given in red solid circles and perturbed state for NAA signal is given in blue solid circles.

\subsection{Analysis of the LEP Event}

In perturbed ionospheric conditions at the Belgrade receiver site $\left(44.85^{\circ} \mathrm{N}, 20.38^{\circ} \mathrm{E}\right)$, an increase in phase delay and decrease in amplitude for both analysed VLF signals, are registered (Figures 4 and 10). Such behaviour can be explained by lowering the VLF signal reflection height (delay in the phase is less) and, respectively, by reducing the sharpness of the ionized environment lower edge. In perturbed waveguides, modal minima are mitigated compared to the unperturbed ionospheric state. In the perturbed NAA waveguide, reflection height decreased from $86.5 \mathrm{~km}$ (characteristic value for normal unperturbed nighttime ionospheric conditions) to $86 \mathrm{~km}$, while reflection edge sharpness decreased from $0.46 \mathrm{~km}^{-1}$ (characteristic value for normal unperturbed night-time ionospheric conditions) to $0.36 \mathrm{~km}^{-1}$, which is a value characteristic for daytime ionospheric conditions. Changes in GQD propagation are similar: in perturbed waveguide, reflection height decreased from $86.5 \mathrm{~km}$ to $85.8 \mathrm{~km}$, while reflection edge sharpness decreased from $0.46 \mathrm{~km}^{-1}$ to $0.38 \mathrm{~km}^{-1}$ (value characteristic for daytime ionospheric conditions). A less sharp lower edge of the ionized environment enables the VLF signal to penetrate into the ionized environment, and the same time, VLF signal deviant energy absorption takes place. It is well known that $\beta$ is a function of $\omega$. After an LEP event, an NAA signal pair $\left(\beta / H^{\prime}\right)$ have values $\left(0.46 \mathrm{~km}^{-1} / 86.5 \mathrm{~km}\right)$ and GQD have values $\left(0.46 \mathrm{~km}^{-1} / 86.6 \mathrm{~km}\right)$, so it can be said that the ionosphere is fully recovered. Same ionospheric conditions $\left(\left(\beta / H^{\prime}\right)\right.$ have values of $\left.0.46 \mathrm{~km}^{-1} / 86.5 \mathrm{~km}\right)$ that apply for areas outside of the irregularity, too. Obtained values of $\left(\beta / H^{\prime}\right)$ pairs are in agreement with [48], who reported $\beta$ in the range $0.48-0.5 \mathrm{~km}^{-1}$ and $H^{\prime}$ in the range $85.3-87 \mathrm{~km}$ for cases of short signals with a mid-latitudinal transmission, also with [57] who reported $\beta$ in the range $0.46-0.5 \mathrm{~km}^{-1}$ and $H^{\prime}$ in the range $84-87 \mathrm{~km}$ for cases of short and moderate length signals in most cases with mid-latitudinal transmission, and [54], who reported $\beta$ in the range $0.307-0.42 \mathrm{~km}^{-1}$ and $H^{\prime}$ in the range $80.3-87 \mathrm{~km}$ for cases of short length signals in most cases with mid-latitudinal transmission. An obtained relative change in reflection height during analysed perturbation of $0.5 \mathrm{~km}$ and 
$0.7 \mathrm{~km}$ in cases of NAA and GQD signals, respectively, are in agreement with the results reported by [54,55] who reported ranges of 7-10 km and 3.7-6.7 km, respectively. Measured and simulated relative change in amplitude and phase delay values (Table 1) are in line with [18] and reference therein, an amplitude difference $\sim 6 \mathrm{~dB}$ and $\sim 20 \mathrm{deg}$ of phase shift and $[48,54]$ who reported relative measured and modelled amplitude and phase change of 1.4 and $1.5 \mathrm{~dB}$ and 9 and $8 \mathrm{deg}$ and up to 2.01 and $1.74 \mathrm{~dB}$ and 3.63 and $3.15 \mathrm{deg}$, respectively. Calculated maximum electron density values (for NAA signal $\mathrm{N}_{\text {e pert }}(86.5 \mathrm{~km})=$ $3.65 \times 10^{7} \mathrm{~m}^{-3}$ and $\mathrm{N}_{\mathrm{e}}$ unpert $(86 \mathrm{~km})=3.39 \times 10^{7} \mathrm{~m}^{-3}$ and for GQD signal $\mathrm{N}_{\text {e pert }}(86.5 \mathrm{~km})$ $=3.76 \times 10^{7} \mathrm{~m}^{-3}$ and $\mathrm{N}_{\mathrm{e}}$ unpert $\left.(85.8 \mathrm{~km})=3.39 \times 10^{7} \mathrm{~m}^{-3}\right)$ are in agreement with [48] who reported $\mathrm{N}_{\mathrm{e}}$ unpert $(87 \mathrm{~km})=3.14 \times 10^{7} \mathrm{~m}^{-3}$ and $\mathrm{N}_{\text {e pert }}(85.3 \mathrm{~km})=3.67 \times 10^{7} \mathrm{~m}^{-3}$, while [54] reported higher values and a steeper slope (variation of $\mathrm{N}_{\text {e pert }}(84 \mathrm{~km})$ from ambient $\mathrm{N}_{\mathrm{e}}$ unpert $(84 \mathrm{~km})$ reported $1.519 \times 10^{8}$ and $0.607 \times 10^{8} \mathrm{~m}^{-3}$, respectively). The errors, introduced by the technique used, place the uncertainty of the results between $10 \%$ and 25\% (see, e.g., [23]). More precisely we estimate that the total error, i.e., noise error and the calibration error is $\sim 5 \%$ in amplitude and phase delay, which is in agreement with [58]. Moreover, the absolute amplitude variation between the recorded values and the signal amplitude and phase values acquired using LWPC is usually $10-20 \%$ which gives uncertainty of the results between $10 \%$ and $25 \%$. Electron densities and ionospheric parameters obtained by different models and techniques $[23,30,47,59]$ vary by about one order of magnitude (factor 10). Electron density ratios related to flare Ixmax given in [60] are within one order of magnitude and for unperturbed flare conditions given in [61] are smaller. Results obtained by VLF technique and LWPCV2.1 software are satisfactory for conducted qualitative analysis presented in this work.

By NAA signal trace modelling, it was found that ionospheric irregularity related to LIE outreach from $4920 \mathrm{~km}$ to $5800 \mathrm{~km}$ when looking along the GCP path from transmitter to receiver, thus, LIE extent is $880 \mathrm{~km}$, with corresponding coordinates $\left(0.7^{\circ} \mathrm{E}, 51.5^{\circ} \mathrm{N}\right)$ and $\left(12^{\circ} \mathrm{E}, 48.3^{\circ} \mathrm{N}\right)$. By GQD signal trace modelling, ionospheric irregularity outreach was found from $780 \mathrm{~km}$ to $1440 \mathrm{~km}$ when looking along the GCP path from transmitter to receiver, thus, LIE extent is $660 \mathrm{~km}$, with corresponding coordinates $\left(7.4^{\circ} \mathrm{E}, 51.4^{\circ} \mathrm{N}\right)$ and $\left(14.9^{\circ} \mathrm{E}, 48^{\circ} \mathrm{N}\right)$. Modelled LIE extent for both cases is in agreement with [54,57] who reported precipitation patches estimated as at least $1500 \times 600 \mathrm{~km}$ and spatial extent of disturbance as $728 \mathrm{~km}$, respectively. Assumed geographical position of modelled irregularity in NAA and GQD waveguides, i.e., electron density increases in D-region due to energetic electron precipitation (see Figure 9), is presented by a blue oval in Figure 11, indicating that energetic electron precipitation took place over central Europe.

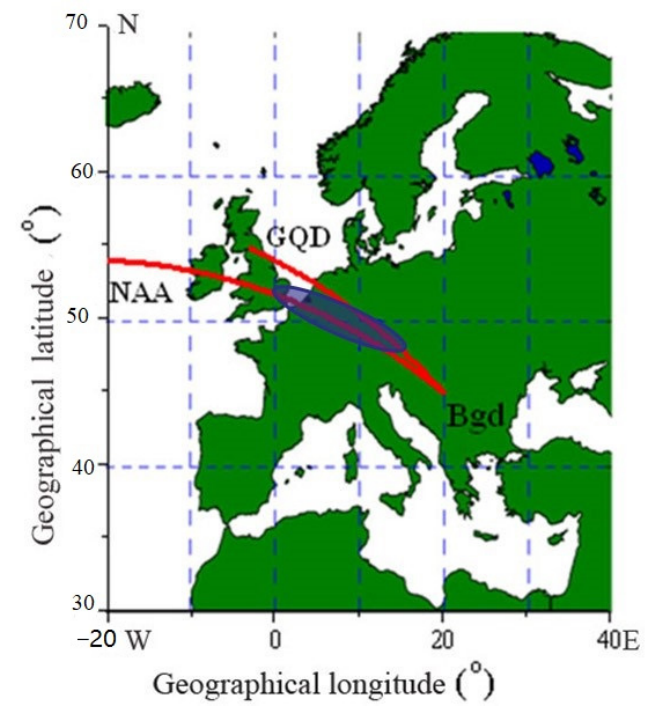

Figure 11. Geographical position of modelled LIE (blue oval) related to energetic electron precipitation on 16 November 2004. 


\section{Conclusions and Perspectives}

Ionospheric conditions highly differ depending on the time of day when sudden disturbances occur, with a transition period between stable daytime and stable night-time ionospheric conditions, i.e., during dawn and sunset being especially challenging for modelling. Regular night-time ionospheric conditions are described with parameter pairs $\left(\beta, H^{\prime}\right)$ within a range of values, that is $0.47-0.50 \mathrm{~km}^{-1}$ and $50-87 \mathrm{~km}$, respectively, while in unperturbed daytime ionospheric conditions, this pair is defined only by one pair $\left(0.3 \mathrm{~km}^{-1}\right.$, $74 \mathrm{~km}$ ). In the case of perturbation presence, ionospheric conditions are changed affecting VLF transmission within the Earth-ionosphere waveguide, inducing signal's amplitude and phase delay to deviate from their regular values. In such disturbed environment, parameter pairs $\left(\beta, H^{\prime}\right)$ also deviate from their regular values, depicting the change in electron density that takes place, following the causative agent's behaviour. In the case of the examined LEP event example, parameter pairs $\left(\beta, H^{\prime}\right)$ changed according to perturbed nocturnal waveguides. Specifically, in the case of the NAA signal parameter, $H^{\prime}$ went through a decrease from $86.5 \mathrm{~km}$ (characteristic value for normal unperturbed nighttime ionospheric conditions in pre-LEP state) to $86 \mathrm{~km}$ at LEP's peak and returned to its regular value of $86.5 \mathrm{~km}$ in post-LEP conditions, while parameter reflection edge sharpness $\beta$ decreased from $0.46 \mathrm{~km}^{-1}$ (characteristic value for normal unperturbed night-time ionospheric conditions before LEP occurrence) to $0.36 \mathrm{~km}^{-1}$ at LEP's peak, which is the value characteristic for daytime ionospheric conditions and returned to $0.46 \mathrm{~km}^{-1}$, its regular value after the influence of the LEP event. Similar behaviour is also present in the case of GQD trace, where parameter $H^{\prime}$ went through a decrease from $86.5 \mathrm{~km}$ to $85.8 \mathrm{~km}$ at LEP's peak and returned to $86.6 \mathrm{~km}$, while reflection edge sharpness $\beta$ decreased from $0.46 \mathrm{~km}^{-1}$ to $0.38 \mathrm{~km}^{-1}$ and returned to $0.46 \mathrm{~km}^{-1}$. It can be concluded that after the influence of the analysed LEP event, the ionosphere is fully recovered in both waveguides, still remaining slightly higher, reflecting the edge height in the case of the GQD signal. Electron density change is one order of magnitude below regular values.

Regarding measured $\Delta A(\mathrm{~dB})$ and $\Delta P\left(^{\circ}\right)$, in the case of the LEP event, they are in a range of -1 to $-2 \mathrm{~dB}$ and +9 to $+13^{\circ}$ (where the minus sign denotes decrease and plus sign increase in signal values compared to pre-LEP state). In the case of mid- and strong flare events, $\Delta A(\mathrm{~dB})$ and $\Delta P\left({ }^{\circ}\right)$ are usually of higher values [38,62,63], and especially in X-class flare events such as the one analysed here, where they took values of about $+4 \mathrm{~dB}$ and $+159^{\circ}$, respectively. At the maximum X-ray irradiance during X1.3 class flare event that occurred on 7 September 2017, as the response within lower ionosphere, the reflecting edge height decreased by $13 \mathrm{~km}$ to the height $63 \mathrm{~km}$, and the reflection edge sharpness increased to the value $0.42 \mathrm{~km}^{-1}$, while the induced electron density increase reached almost two orders of magnitude compared to the regular value. The analysed flare event lasted for almost two hours, while it took much longer for the lower ionosphere to fully recover.

Data related to the ionospheric research and the results obtained are of great use for various Earth observations and especially for telecommunications, while they also can be significant to other applications in modern society. Modelling ionospheric parameters is crucial for validation of proposed models. Results presented in this paper are related to modelling the plasma response of the ionospheric lowest region, to some high energy events, as recorded by radio signals. The presented results are important for the modelling of this region but also useful for future atmospheric aerosol-electricity interactions research in climate science. Monitoring and observing ionospheric characteristics related to the mid-latitude European ionosphere using VLF signals is particularly important, especially bearing in mind that beside the Hungarian system, this is the only available source of such data [64]. The computational results can differ by a factor of ten depending on which method is used, thus it is important to present new modelling results and make comparisons to the results obtained by the same or similar technique. The findings are significant in light of possible future collaboration on VLF studies in this part of Europe. 
Author Contributions: Conceptualization, A.K.; writing-original draft preparation, A.K.; writingreview and editing A.K., V.A.S. and Z.R.M. The authors had full access to the data and take responsibility for their integrity. All authors have read and agreed to the published version of the manuscript.

Funding: This work was funded by the Institute of Physics Belgrade through a grant by the Ministry of Education, Science, and Technological Development of the Republic of Serbia. This article/publication is based upon work from COST Action CA17126-Towards understanding and modelling intense electronic excitation (TUMIEE), supported by COST (European Cooperation in Science and Technology).

Institutional Review Board Statement: Not applicable.

Informed Consent Statement: Not applicable.

Data Availability Statement: VLF data recorded at the Institute of Physics, University of Belgrade, Belgrade, Serbia can be obtained upon a request. Please contact V.A.S.

Acknowledgments: Authors thank D. Šulić for instrumental set-up and useful discussions.

Conflicts of Interest: The authors declare no conflict of interest. The funders had no role in the design of the study; in the collection, analyses, or interpretation of data; in the writing of the manuscript, or in the decision to publish the results.

\section{References}

1. Kelley, M.C. The Earth's Ionosphere: Plasma Physics and Electrodynamics; Academic Press: Oxford, UK, 2009.

2. Rycroft, M.J. Electrical processes coupling the atmosphere and ionosphere: An overview. J. Atmos. Sol. Terr. Phys. 2006, 68, 445-456. [CrossRef]

3. Kourtidis, K.; André, K.S.; Karagioras, A.; Nita, I.-A.; Sátori, G.; Bór, J.; Kastelis, N. The influence of circulation weather types on the exposure of the biosphere to atmospheric electric fields. Int. J. Biometeorol. 2021, 65, 93-105. [CrossRef]

4. Cummer, S.A.; Inan, U.S. Ionospheric E region remote sensing with ELF radio atmospherics. Radio Sci. 2000, 35, 1437-1444. [CrossRef]

5. Mannucci, A.J.; Hajj, G.A.; Iijima, B.A.; Komjathy, A.; Meehan, T.K.; Pi, X.Q.; Srinivasan, J.; Tsurutani, B.T.; Wilson, B.; Zhang, L.D. GPS-based remote sensing of the geospace environment: Horizontal and vertical structure of the ionosphere and plasmasphere. In Proceedings of the Instruments, Science, and Methods for Geospace and Planetary Remote Sensing, Honolulu, HI, USA, 30 December 2004; pp. 1-13.

6. Goodman, J.M. Space Weather \& Telecommunications; Springer: New York, NY, USA, 2005; Volume 382.

7. Tandberg-Hanssen, E.; Emslie, A.G. The Physics of Solar Flares; Cambridge University Press: Cambridge, UK, 1988 ; Volume 14.

8. Berényi, K.; Barta, V.; Kis, Á. Midlatitude ionospheric F2-layer response to eruptive solar events-caused geomagnetic disturbances over Hungary during the maximum of the solar cycle 24: A case study. Adv. Space Res. 2018, 61, 1230-1243. [CrossRef]

9. Šulić, D.; Srećković, V.; Mihajlov, A. A study of VLF signals variations associated with the changes of ionization level in the D-region in consequence of solar conditions. Adv. Space Res. 2016, 57, 1029-1043. [CrossRef]

10. Šulić, D.; Srećković, V. A comparative study of measured amplitude and phase perturbations of VLF and LF radio signals induced by solar flares. Serb. Astron. J. 2014, 188, 45-54. [CrossRef]

11. Reid, G.C. Ion Chemistry in the D Region; Academic Press: Cambridge, MA, USA, 1976; Volume 12, pp. 375-413.

12. Brasseur, G.P.; Solomon, S. Aeronomy of the Middle Atmosphere: Chemistry and Physics of the Stratosphere and Mesosphere; Springer Science \& Business Media: Dordrecht, The Netherlands, 2006; Volume 32.

13. Nicolet, M.; Aikin, A. The formation of the D region of the ionosphere. J. Geophys. Res. 1960, 65, 1469-1483. [CrossRef]

14. Nunn, D. On the numerical modelling of the VLF Trimpi effect. J. Atmos. Sol. Terr. Phys. 1997, 59, 537-560. [CrossRef]

15. Helliwell, R.; Katsufrakis, J.; Trimpi, M. Whistler-Induced Amplitude Perturbations in VLF Propagation. J. Geophys. Res. 1973, 78, 4679-4688. [CrossRef]

16. Helliwell, R.A. Whistlers and Related Ionospheric Phenomena; Stanford University Press Stanford: Palo Alto, CA, USA, 1965; Volume 50.

17. Strangeways, H. Lightning, Trimpis and Sprites; Oxford University Press: Oxford, UK, 1996; Volume 1993, pp. 741-780.

18. Silber, I.; Price, C. On the use of VLF narrowband measurements to study the lower ionosphere and the mesosphere-lower thermosphere. Surv. Geophys. 2017, 38, 407-441. [CrossRef]

19. Trichtchenko, L.; Zhukov, A.; Van der Linden, R.; Stankov, S.; Jakowski, N.; Stanisławska, I.; Juchnikowski, G.; Wilkinson, P.; Patterson, G.; Thomson, A. November 2004 space weather events: Real-time observations and forecasts. Space Weather 2007, 5, 1-17. [CrossRef]

20. Rodger, C.J. Subionospheric VLF perturbations associated with lightning discharges. J. Atmos. Sol. Terr. Phys. 2003, 65, 591-606. [CrossRef] 
21. Belenkiy, M.; Orlov, A.; Petrova, G.; Uvarov, A. Modeling of the electron density profile of the lower ionosphere (45-75 km) for sudden ionospheric disturbance conditions based on the data on sudden phase anomalies of VLF signals. Int. J. Geomag. Aeron. 2006, 6, GI3007. [CrossRef]

22. McKinnell, L.-A.; Friedrich, M. A neural network-based ionospheric model for the auroral zone. J. Atmos. Sol. Terr. Phys. 2007, 69, 1459-1470. [CrossRef]

23. Žigman, V.; Grubor, D.; Šulić, D. D-region electron density evaluated from VLF amplitude time delay during X-ray solar flares. J. Atmos. Sol. Terr. Phys. 2007, 69, 775-792. [CrossRef]

24. Chakrabarti, S.; Pal, S.; Sasmal, S.; Mondal, S.; Ray, S.; Basak, T.; Maji, S.; Khadka, B.; Bhowmick, D.; Chowdhury, A. VLF campaign during the total eclipse of July 22nd, 2009: Observational results and interpretations. J. Atmos. Sol. Terr. Phys. 2012, 86, 65-70. [CrossRef]

25. Thomson, N.R.; Rodger, C.J.; Clilverd, M.A. Daytime D region parameters from long-path VLF phase and amplitude. J. Geophys. Res. 2011, 116, 1-12.

26. McRae, W.M.; Thomson, N.R. VLF phase and amplitude: Daytime ionospheric parameters. J. Atmos. Sol. Terr. Phys. 2000, 62, 609-618. [CrossRef]

27. McRae, W.M.; Thomson, N.R. Solar flare induced ionospheric D-region enhancements from VLF phase and amplitude observations. J. Atmos. Sol. Terr. Phys. 2004, 66, 77-87. [CrossRef]

28. Thomson, N.R.; Rodger, C.J.; Clilverd, M.A. Large solar flares and their ionospheric D region enhancements. J. Geophys. Res. 2005, $110,1-10$

29. Thomson, N.R.; Clilverd, M.A.; McRae, W.M. Nighttime ionospheric D region parameters from VLF phase and amplitude. J. Geophys. Res. 2007, 112, 1-14.

30. Basak, T.; Chakrabarti, S.K. Effective recombination coefficient and solar zenith angle effects on low-latitude D-region ionosphere evaluated from VLF signal amplitude and its time delay during X-ray solar flares. Astrophys. Space. Sci. 2013, 348, 315-326. [CrossRef]

31. Budden, K. Radio Waves in the Ionosphere; Cambridge Univ. Press: Cambridge, UK, 1961.

32. Budden, K.G. The Wave-Guide Mode Theory of Wave Propagation; Logos Press: London, UK, 1961.

33. Wait, J.R. Electromagnetic Waves in Stratified Media; Pergamon Press: Oxford, UK, 1970; Volume 3.

34. Mitra, A.P. Ionospheric Effects of Solar Flares; Springer: Berlin/Heidelberg, The Netherlands, 1974; Volume 46.

35. Balan, N.; Alleyne, H.; Walker, S.; Reme, H.; McCrea, I.; Aylward, A. Magnetosphere-ionosphere coupling during the CME events of 07-12 November 2004. J. Atmos. Sol. Terr. Phys. 2008, 70, 2101-2111. [CrossRef]

36. Inan, U.S.; Lehtinen, N.G.; Moore, R.; Hurley, K.; Boggs, S.; Smith, D.; Fishman, G. Massive disturbance of the daytime lower ionosphere by the giant $\gamma$-ray flare from magnetar SGR 1806-20. Geophys. Res. Lett. 2007, 34, 8103-8108. [CrossRef]

37. Žigman, V.; Kudela, K.; Grubor, D. Response of the Earth's lower ionosphere to the ground level enhancement event of December 13, 2006. Adv. Space Res. 2014, 53, 763-775. [CrossRef]

38. Srećković, V.A.; Šulić, D.M.; Ignjatović, L.; Vujčić, V. Low Ionosphere under Influence of Strong Solar Radiation: Diagnostics and Modeling. Appl.Sci. 2021, 11, 7194. [CrossRef]

39. Nina, A.; Srećković, V.; Radovanović, M. Multidisciplinarity in research of extreme solar energy influences on natural disasters Sustainability 2019, 11, 974. [CrossRef]

40. Cannon, P.; Angling, M.; Barclay, L.; Curry, C.; Dyer, C.; Edwards, R.; Greene, G.; Hapgood, M.; Horne, R.B.; Jackson, D. Extreme Space Weather: Impacts on Engineered Systems and Infrastructure; Royal Academy of Engineering: Carlton House Terrace, London, 2013.

41. McMorrow, D. Impacts of Severe Space Weather on the Electric Grid; JASON: McLean, VA, USA, 2011; pp. $22102-27508$.

42. Kolarski, A.; Grubor, D. Sensing the Earth's low ionosphere during solar flares using VLF signals and goes solar X-ray data. Adv. Space Res. 2014, 53, 1595-1602. [CrossRef]

43. Kolarski, A.; Grubor, D. Comparative analysis of VLF signal variation along trajectory induced by X-ray solar flares. J. Astrophys. Astr. 2015, 36, 565-579. [CrossRef]

44. Kolarski, A.; Grubor, D.; Šulić, D. Diagnostics Of The Solar X-Flare Impact On Lower Ionosphere Through The Vlf-Naa Signal Recordings. Open Astron. 2011, 20, 591-595. [CrossRef]

45. Nina, A.; Čadež, V.; Srećković, V.; Šulić, D. The influence of solar spectral lines on electron concentration in terrestrial ionosphere. Open Astron. 2011, 20, 609-612. [CrossRef]

46. Nina, A.; Čadež, V.; Srećković, V.; Šulić, D. Altitude distribution of electron concentration in ionospheric D-region in presence of time-varying solar radiation flux. Nucl. Instrum. Meth. B 2012, 279, 110-113. [CrossRef]

47. Nina, A.; Čadež, V.; Šulić, D.; Srećković, V.; Žigman, V. Effective electron recombination coefficient in ionospheric D-region during the relaxation regime after solar flare from 18 February 2011. Nucl. Instrum. Meth. B 2012, 279, 106-109. [CrossRef]

48. Šulić, D.; Nina, A.; Srećković, V. Numerical Simulations Of The Effect Of Localised Ionospheric Perturbations On Subionospheric VLF Propagation. arXiv 2014, arXiv:1405.3783.

49. Nina, A.; Čadež, V.M.; Popović, L.Č.; Srećković, V.A. Diagnostics of plasma in the ionospheric D-region: Detection and study of different ionospheric disturbance types. Eur. Phys. J. D 2017, 71, 189. [CrossRef]

50. Nina, A.; Simić, S.; Srećković, V.A.; Popović, L.Č. Detection of short-term response of the low ionosphere on gamma ray bursts. Geophys. Res. Lett. 2015, 42, 8250-8261. [CrossRef] 
51. Ferguson, J. Computer Programs for Assessment of Long-Wavelength Radio Communications, Version 2.0: User's Guide and Source Files; Space and Naval Warfare Systems Center: San Diego, CA, USA, 1998.

52. Gavrilov, B.; Ermak, V.; Lyakhov, A.; Poklad, Y.V.; Rybakov, V.; Ryakhovsky, I. Reconstruction of the Parameters of the Lower Midlatitude Ionosphere in M-and X-Class Solar Flares. Geomagn. Aeron. 2020, 60, 747-753. [CrossRef]

53. Kumar, A.; Kumar, S. Solar flare effects on D-region ionosphere using VLF measurements during low-and high-solar activity phases of solar cycle 24. Earth Planets Space 2018, 70, 29. [CrossRef]

54. Kerrache, F.; Nait Amor, S.; Kumar, S. Ionospheric D region disturbances due to FAC and LEP associated with three severe Geomagnetic Storms as observed by VLF Signals. J. Geophys. Res. 2021, 126, e2020JA027838. [CrossRef]

55. Šulić, D.; Žigman, V.; Nina, A. Study of the observed amplitude and phase perturbations on VLF signals from lighting induced electron precipitation and reconstruction of D-region electron density height profile. In Proceedings of the 4rd VERSIM Workshop 2010, Prague, Czech Republic, 13-17 September 2010.

56. Wait, J.R.; Spies, K.P. Characteristics of the Earth-Ionosphere Waveguide for VLF Radio Waves; US Department of Commerce, National Bureau of Standards: Boulder, CO, USA, 1964; Volume 13.

57. Clilverd, M.A.; Nunn, D.; Lev-Tov, S.J.; Inan, U.S.; Dowden, R.L.; Rodger, C.J.; Smith, A.J. Determining the size of lightninginduced electron precipitation patches. J. Geophys. Res. 2002, 107, SIA 10-SIA 11. [CrossRef]

58. Bainbridge, G.; Inan, U.S. Ionospheric D region electron density profiles derived from the measured interference pattern of VLF waveguide modes. Radio Sci. 2003, 38, 16-11-16-21. [CrossRef]

59. Palit, S.; Basak, T.; Mondal, S.; Pal, S.; Chakrabarti, S. Modeling of very low frequency (VLF) radio wave signal profile due to solar flares using the GEANT4 Monte Carlo simulation coupled with ionospheric chemistry. Atmos. Chem. Phys. 2013, 13, 9159-9168. [CrossRef]

60. Grubor, D.; Šulić, D.; Žigman, V. Classification of X-ray solar flares regarding their effects on the lower ionosphere electron density profile. Ann. Geophys. 2008, 26, 1731-1740. [CrossRef]

61. Nina, A.; Čadež, V.M. Electron production by solar Ly- $\alpha$ line radiation in the ionospheric D-region. Adv. Space Res. 2014, 54, 1276-1284. [CrossRef]

62. Bouderba, Y.; NaitAmor, S.; Tribeche, M. Study of the solar flares effect on VLF radio signal propagating along NRK-ALG path using LWPC code. J. Geophys. Res. 2016, 121, 6799-6807. [CrossRef]

63. Feng, J.; Han, B.; Gao, F.; Zhang, T.; Zhao, Z. Analysis of Global Ionospheric Response to Solar Flares Based on Total Electron Content and Very Low Frequency Signals. IEEE Access 2021, 9, 57618-57631. [CrossRef]

64. Barta, V.; Haldoupis, C.; Sátori, G.; Buresova, D.; Chum, J.; Pozoga, M.; Berényi, K.A.; Bór, J.; Popek, M.; Kis, Á. Searching for effects caused by thunderstorms in midlatitude sporadic E layers. J. Atmos. Sol. Terr. Phys. 2017, 161, 150-159. [CrossRef] 